\title{
EL ESTATUS JURÍDICO INTERNACIONAL DE LOS PRISIONEROS DETENIDOS POR ESTADOS UNIDOS DE AMÉRICA EN GUANTÁNAMO, CUBA, A RAÍZ DEL CONFLICTO EN AFGANISTÁN*
}

\section{Luis BENAVIDES**}

Resumen: Estados Unidos de América (EUA) ha detenido a cientos de personas desde el inicio de su campaña militar en Afganistán. Muchos de ellos han sido enviados a la base militar estadounidense en Guantánamo, Cuba, donde permanecen en una especie de limbo legal esperando ser enjuiciados ante unas muy cuestionables comisiones militares. El autor hace un análisis comparativo entre, por una parte, la práctica de EUA con respecto al tratamiento dado a las personas detenidas en Guantánamo, y el marco legal creado para el establecimiento de las comisiones militares, y por otra parte, el derecho internacional humanitario, al que EUA está obligado a respetar. De esta manera se demuestra el estatus jurídico que deben gozar las personas detenidas en Guantánamo, y la violación de parte de EUA de sus obligaciones internacionales.

ABSTRACT: Hundreds of people have been detained by the United States since the beginning of the military campaign in Afghanistan. Many of them have been sent to the American military base in Guantanamo, Cuba, where they remain in a sort of legal limbo waiting for possible trials before very questionable military commissions. The author makes a comparative analysis, on one hand, between the practice of the United States regarding the treatment of the Guantanamo detainees and the legal framework for the establishment of military commissions and, on the other hand, the International Humanitarian Law, which the United States is obliged to comply with. The author points out the legal status that the Guantanamo detainees are entitle to and the breach of the United States international obligations.

RÉSumÉ: Des centaines de personnes ont été arrêtées par les Etats-Unis depuis le début de sa campagne militaire en Afghanistan. Un grand nombre d'entre eux a été envoyé à la base militaire nord-américaine à Guantanamo, Cuba, où ils restent dans une espèce de vide juridique, en l'attente d'être soumis à un procès devant des très douteuses commissions militaires. L'auteur fait une analyse comparative entre d'une part la pratique des Etats-Unis sur le traitement octroyé aux personnes détenues à Guantanamo et le cadre juridique crée pour l'établissement des commissions militaires et d'autre part le Droit international humanitaire, que les Etats-Unis sont obligés à respecter; et en décrivant le statut juridique dont les personnes détenues à Guantanamo doivent jouir, il démontre la violation de la part des Etats-Unis de ses obligations internationales.

* Ponencia presentada en el seminario internacional "El derecho internacional y los acontecimientos del 11 de septiembre", México, mayo de 2002.

** Doctorando del Institut Universitaire de Hautes Études Internationales; Ginebra, Suiza. 
The USA claims to be a progressive force for human rights. Military commissions have not been used for more than half a century in the United States, a period which has seen the reinforcement of a broad framework of fair trial guarantees in international human rights law and standards and in international humanitarian law. Executive military commissions have no place in 21 st century criminal justice systems. ${ }^{1}$

SUMARIO: I. Introducción. II. El estatus jurídico de los prisioneros de Guantánamo. III. Breve explicación del subsistema de derecho internacional humanitario (DIH). IV. Relación entre derechos humanos y DIH. V. Los prisioneros de guerra, marco general. VI. Derechos de los prisioneros de guerra. VII. Comisiones militares. VIII. Conclusiones.

\section{INTRODUCCIÓN}

Los acontecimientos del 11 de septiembre en Estados Unidos de América (EUA) tuvieron como respuesta en el plano militar, ${ }^{2}$ por parte de EUA y una coalición de Estados, ${ }^{3}$ el ataque armado a Afganistán. Las razones, alega EUA, se encuentran en el rechazo, por parte del gobierno de facto de los talibanes, de entregar a quien consideran ser el autor intelectual de dichos atentados, Osama bin Laden, así como a los miembros del grupo que lidera llamado Al Qaeda.

EUA alega tener pruebas suficientes que vinculan a Osama bin Laden y a miembros de Al Qaeda con ataques previos al World Trade Center en Nueva York y a sus embajadas en Tanzania y Kenya. Además, señalan que el grupo Al Qaeda es una red internacional de terroristas cuyo objetivo no es sólo EUA sino, reduciendo al máximo el argumento, la cultura occidental.

1 Amnistía Internacional, United States of America. Memorandum to the US Government on the rights of people in US custody in Afghanistan and Guantánamo Bay. AI Index: AMR 51/053/2002, abril de 2002, p. 61 (Amnistía Memorandum).

2 La estrategia de Estados Unidos de América se ha desarrollado en diferentes planos, por ejemplo, en el plano diplomático la intención ha sido crear el mayor apoyo posible, colocando a los países ante la disyuntiva de estar con Estados Unidos de América o en contra de Estados Unidos de América; en el plano económico se trata de detectar y romper cualquier tipo de financiamiento a grupos terroristas.

3 El principal aliado militar de Estados Unidos de América es Gran Bretaña, pero también han participado de manera directa tropas de Canadá y Alemania, entre otros países. De manera indirecta han participado básicamente todos los países vecinos de Afganistán, destacando su otrora aliado Pakistán. 
Desde el inicio de los combates en Afganistán en octubre de 2001, miles de personas han sido detenidas por la coalición internacional que encabeza EUA ${ }^{4}$ y por las fuerzas anti-talibanes, las cuales ahora forman el nuevo gobierno de Afganistán.

Los prisioneros se encuentran encarcelados en diversos centros de detención en Afganistán ${ }^{5}$ y Pakistán e incluso en barcos militares estadounidenses. ${ }^{6}$ Esto, por supuesto, hace más difícil saber el número exacto de prisioneros y las condiciones en las que se encuentran. En dichos centros, los prisioneros son sometidos por las fuerzas estadounidenses a una serie de interrogatorios, con la finalidad de seleccionar a aquellos que les pudiesen proporcionar información que los lleve a la captura de los líderes de la organización Al Qaeda o de los talibanes, o bien que hayan formado parte importante de dichas organizaciones o hubieren tenido alguna relación con los hechos de septiembre 11. Una vez seleccionados los prisioneros, son trasladados a la base militar de EUA, en Guantánamo, Cuba, para un posible juicio ante las comisiones militares. ${ }^{7}$ Respecto al destino de los miles de prisioneros que se encuentran en Afganistán, es aún más incierto. ${ }^{8}$

El número de detenidos en Guantánamo es alrededor de 384. Mientras que 174 más, esperan traslado en Afganistán. ${ }^{9}$

EUA ha calificado a priori a las personas detenidas en Guantánamo de terroristas y criminales, por lo que en su opinión serían combatientes ilegales. En cambio, la gran mayoría de la comunidad internacional opina que dichas personas deberían gozar claramente del estatus de prisioneros de guerra.

4 Entre las personas capturadas se encuentran nacionales de más de 35 países. De la mayoría de ellas se desconoce su identidad. Véase Amnistía Memorandum, op. cit., nota 1, p. 23.

5 La instalación con mayor número de prisioneros, varios miles, se encuentra en Shiburghan, al oeste de Mazar-i-Sharif. Otro campo de detención controlado por los estadounidenses se encuentra a las afueras de Kandahar. Existen muchas otras prisiones en todo el territorio afgano, algunas de ellas controladas por las fuerzas anti-talibanes.

6 Por ejemplo, el USS Peleliu.

7 El secretario de defensa Ronald Rumsfeld ha señalado que las personas que se encuentran en Guantánamo son las más probables de ser enjuiciadas ante las comisiones militares. Respecto a los demás no se ha decidido que van a hacer con ellos. Incluso se ha señalado la posibilidad de detenerlos indefinidamente.

8 Se ha hablado de algunos posibles juicios por parte del nuevo gobierno afgano, pero muy poco se sabe sobre el número exacto de las personas detenidas, las condiciones en las que se encuentran, su localización y lo que se hará con ellas.

9 CNN, "Guantanamo facilities full, building goes on. Gitmo now holds 384 detainees; 174 more in Afganistán", 10 de mayo de 2002, en http://www.cnn.com/2002/WORLD/americas/05/10/gitmo.detainees/index.html. Visitado el 11 de mayo de 2002. 
El problema que se presenta es saber cuál es el estatus, conforme al derecho internacional, de las personas detenidas en Guantánamo. Esto nos determinará los derechos que les son conferidos a dichas personas, así como las obligaciones que tiene EUA respecto de las mismas.

\section{EL ESTATUS JURÍDICO DE LOS PRISIONEROS DE GUANTÁNAMO}

Para determinar el estatus jurídico de los prisioneros detenidos en Guantánamo es indispensable saber las circunstancias en las cuales fueron aprehendidos.

La mayoría de las personas que se encuentran en Guantánamo fueron detenidas en el contexto de un conflicto armado entre EUA, junto con una coalición internacional, en contra del gobierno de facto de los talibanes en Afganistán. Junto a los talibanes pelearon supuestamente miembros de la organización Al Qaeda.

Existe, sin embargo, un pequeño grupo de personas que fueron detenidos en otros lugares. Tal es el caso de los argelinos detenidos en Bosnia y que pese a que la Corte Suprema de ese país había declarado que no existían elementos para detener a esas personas, éstas fueron transportadas, ilegalmente, a la base de Guantánamo. ${ }^{10}$ También se han reportado casos de personas que han sido detenidos en Afganistán y luego han sido transferidas a otros países para interrogatorios, en donde incluso se ha mencionado participación de agentes estadounidenses en los mismos. ${ }^{11}$ Estas personas tienen un estatus jurídico diferente a las detenidas durante un conflicto militar, y por ende no las estudiaremos en esta ocasión.

Todo conflicto armado está gobernado por un subsistema de reglas de derecho internacional denominado derecho internacional humanitario (DIH). ${ }^{12}$

10 Véanse comentarios en Amnistía Memorandum, op. cit., nota 1, p. 12.

11 Ibidem, pp. 14-16.

12 El DIH suele llamarse también "derecho de la guerra" o "derecho de los conflictos armados". 


\section{BREVE EXPLICACIÓN DEL SUBSISTEMA DE DERECHO INTERNACIONAL HUMANITARIO (DIH)}

\section{El DIH es un conjunto de normas de carácter convencional o consue-} tudinario y de principios, ${ }^{13}$ que por razones humanitarias trata de limitar los efectos de los conflictos armados. Protege a las personas que no toman parte en las hostilidades, como son los civiles y el personal médico y religioso. Protege asimismo a las personas que ya no participan en los combates, esto es, aquellos que se encuentran hors de combat, por ejemplo, los combatientes heridos o enfermos, los náufragos y los prisioneros de guerra. Asimismo, limita los medios y métodos de hacer la guerra. ${ }^{14}$ El DIH se aplica en situaciones de conflicto armado ${ }^{15}$ de carácter internacional o no internacional, por lo que se le denomina también jus in

13 Algunos principios son: consideraciones elementales de humanidad, necesidad de distinguir entre civiles y combatientes, principio de proporcionalidad, la prohibición de causar sufrimiento innecesario, entre otros.

14 La Corte Internacional de Justicia ha indicado que: "The 'laws and customs of war'... as they were traditionally called... were the subject of efforts at codification undertaken in The Hague (including the Conventions of 1899 and 1907), and were based partly upon the St. Petersburg Declaration of 1868 as well as the results of the Brussels Conference of 1874. This 'Hague Law' and, more particularly, the Regulations Respecting the Laws and Customs of War on Land, fixed the rights and duties of belligerents in their conduct of operations and limited the choice of methods and means of injuring the enemy in an international armed conflict. One should add to this the 'Geneva Law' (the Conventions of 1864, 1906, 1929 and 1949), which protects the victims of war and aims to provide safeguards for disabled armed forces personnel and persons not taking part in the hostilities. These two branches of the law applicable in armed conflict have become so closely interrelated that they are considered to have gradually formed one single complex system, known today as international humanitarian law. The provisions of the Additional Protocols of 1977 give expression and attest to the unity and complexity of that law" Legality of the Threat or Use of Nuclear Weapons, ICJ Reports, 1996, (Advisory Opinion), parágrafo 75. Algunos de los instrumentos internacionales que prohíben el uso de ciertas armas y tácticas militares o que protegen a ciertas categorías de personas o de bienes son: La Convención de la Haya de 1954 para la protección de los bienes culturales en caso de conflicto armado y sus dos protocolos; la Convención de 1972 sobre Armas Bacteriológicas; la Convención de 1980 sobre Ciertas Armas Convencionales, y sus cuatro protocolos; la Convención de 1993 sobre Armas Químicas; el Tratado de Ottawa de 1997 sobre las Minas Antipersona; el protocolo facultativo de la Convención sobre los Derechos del Niño relativo a la participación de niños en los conflictos armados.

15 El Tribunal Internacional para la ex-Yugoslavia ha definido al conflicto armado como: " an armed conflict exists whenever there is a resort to armed force between States or protracted armed violence between governmental authorities and organized armed groups or between such groups within a State. International humanitarian law applies from the initiation of such armed conflicts and extends beyond the cessation of hostilities until a general conclusion of peace is reached; or, in the case of internal conflicts, a peaceful settlement is achieved. Until that moment, international humanitarian law continues to apply in the whole territory of the warring States or, in the case of internal conflicts, the whole territory under the control of a party, whether or not actual combat takes place there", The Prosecutor vs. Dusko Tadic, Appeals Chamber, Case núm. IT-94-AR72, Decision on the Defence Motion for Interlocutory Appeal on Jurisdiction, 2 de octubre de 1995, parágrafo 70 (Caso Tadic). 
bello. Pero no cubre las situaciones de tensiones internas ni de disturbios interiores, como son los actos aislados de violencia. Sólo es aplicable cuando se ha desencadenado un conflicto y se aplica por igual a todas las partes, sin tener en cuenta quien lo inició. El DIH no determina si un Estado tiene o no tiene derecho a recurrir a la fuerza, también conocido como jus ad bellum. ${ }^{16}$ Esta cuestión está regulada por una importante parte - pero distinta - del DIH que figura en la Carta de las Naciones Unidas, artículo 51. En este sentido, tanto EUA al igual que las Naciones Unidas $^{17}$ y la OTAN ${ }^{18}$ han reafirmado el derecho a la legítima defensa después de los ataques del 11 de septiembre. El actual ejercicio por parte de EUA de dicho derecho ha sido muy debatido en la doctrina ${ }^{19}$ debido principalmente a que las condiciones para ejercerlo al igual que la manera en que se ha hecho no corresponden con lo establecido en el derecho internacional general. ${ }^{20}$

16 Para una revisión de los términos jus in bello y jus ad bellum véase: Kolb, Robert, "Origin of the twin terms jus ad bellum/jus in bello", International Review of the Red Cross, núm. 320, 1997.

17 Véanse, por ejemplo, las resoluciones del Consejo de Seguridad de Naciones Unidas: S/Res/1368 (2001) y S/Res/1373 (2001).

18 Cfr. Statement by the North Atlantic Council, Press Release (2001)124, 12 September 2001, en http://www.nato.int/docu/pr/2001/p01-124e.htm.

19 Parte de ese debate se ha dado en foros tales como ASIL insights en http://www.asil.org/insights/insigh77.htm. Véanse, por ejemplo, las contribuciones de Cerone, John, Status of Detainees in International Armed Conflict, and their Protection in the Course of Criminal Proceedings, y Wedgood, Ruth, Tribunals and the events of September 11th.

20 Parte de la crítica también se ha dado debido a un posible uso "preventivo" del derecho a la legítima defensa. Este uso preventivo ya ha tratado de ser invocado por otros Estados en diferentes ocasiones, y ha tenido un gran rechazo por parte de la comunidad internacional. Así, por ejemplo, después del ataque israelita en 1981 en contra de un reactor nuclear iraquí con base en un supuesto derecho "preventivo", las Naciones Unidas condenaron dicho ataque y México declaró: "il est inadmissible d'invoquer le droit de légitime defense quand il n'y a pas eu d'agression armée. Le concept de guerre préventive, qui durant de nombreuses années, a eté utilisé pour justifier les abus des Etats les plus puissants, car il laissait à leur entière discretion le soin de définir ce qui constituait pour eux une menace, a été définitivement aboli par la Charte des Nations Unies", S/PV.2288, 19 de junio de 1981, p. 46, reproducido también en International Legal Materials, 1981, vol. 20, p. 991, y en Cot, Jean-Pierre y Pellet, Alain, La Charte des Nations Unies: commentaire article par article, 2a. ed., France, Economica, 1991, p. 779. Esperamos que el gobierno mexicano siga manteniendo la misma postura. 
El DIH se encuentra esencialmente contenido en los cuatro Convenios de Ginebra de $1949^{21}$ y en sus protocolos adicionales de $1977 .{ }^{22}$ Casi todos los Estados, incluyendo Afganistán y EUA, son parte de dichos convenios. EUA no han ratificado los mencionados protocolos pero muchos de los principios contenidos en ellos se consideran ya parte del derecho consuetudinario internacional y por lo tanto obligatorios para todos los países. Como ya se ha mencionado, una parte importante del DIH se encuentra contenido en el derecho consuetudinario internacional y en los principios del mismo derecho. Así ha quedado reconocido en lo que se conoce como la cláusula Martens. ${ }^{23}$

El DIH distingue entre conflicto armado internacional y conflicto armado sin carácter internacional. En los conflictos armados internacionales se enfrentan, como mínimo, dos Estados. En ellos se deben observar, inter alia, las normas que figuran en los Convenios de Ginebra y en el Protocolo Adicional I.

En los conflictos armados sin carácter internacional se enfrentan, en el territorio de un mismo Estado, las fuerzas armadas regulares y grupos armados disidentes, o grupos armados entre sí. En ellos se aplica una serie más limitada de normas, en particular las disposiciones del artículo 30. común a los cuatro Convenios de Ginebra y el Protocolo Adicional II. ${ }^{24}$

21 I Convenio de Ginebra del 12 de agosto de 1949 para aliviar la suerte que corren los heridos y los enfermos de las Fuerzas Armadas en campaña. 75 UNTS 31 (G-I). II Convenio de Ginebra del 12 de agosto de 1949 para aliviar la suerte que corren los heridos, los enfermos y los náufragos de las fuerzas armadas en el mar. 75 UNTS 85 (G-II). III Convenio de Ginebra del 12 de agosto de 1949 relativo al trato debido a los prisioneros de guerra. 75 UNTS 135 (G-III). III Convenio de Ginebra del 12 de agosto de 1949 relativo a la protección debida a las personas civiles en tiempo de Guerra. 75 UNTS 287 (G-IV).

22 I Protocolo Adicional a los Convenios de Ginebra del 12 de agosto de 1949, relativo a la protección de las víctimas de los conflictos armados internacionales. 1125 UNTS 3 (P-I). II Protocolo Adicional a los Convenios de Ginebra del 12 de agosto de 1949 relativo a la protección de las víctimas de los conflictos armados sin carácter internacional. 1125 UNTS 609 (P-II).

23 "La cláusula de Martens forma parte del derecho de los conflictos armados desde que apareciera, por primera vez, en el Preámbulo del (II) Convenio de La Haya de 1899 relativo a las leyes y costumbres de la guerra terrestre: "Mientras que se forma un Código más completo de las leyes de la guerra, las Altas Partes Contratantes juzgan oportuno declarar que, en los casos no comprendidos en las disposiciones reglamentarias adoptadas por ellas, las poblaciones y los beligerantes permanecen bajo la garantía y el régimen de los principios del derecho de gentes preconizados por los usos establecidos entre las naciones civilizadas, por las leyes de la humanidad y por las exigencias de la conciencia pública". Ticehurst, Rupert, "La cláusula de Martens y el derecho de los conflictos armados", Revista Internacional de la Cruz Roja, núm. 140, 1997, p. 131.

24 Así, dicho artículo tercero indica: "En caso de conflicto armado que no sea de índole internacional y que surja en el territorio de una de las Altas Partes Contratantes, cada una de las Partes en conflicto tendrá la obligación de aplicar, como mínimo, las siguientes disposiciones: 1) Las personas que no participen directamente en las hostilidades, incluidos los miembros de las fuerzas armadas que 
Esta diferencia en la aplicación del DIH, dependiendo del carácter internacional o no del conflicto, parece que se está diluyendo para acercarse cada vez más a una aplicación general del DIH, independientemente de la naturaleza del conflicto. ${ }^{25}$

Como regla general podemos decir que las personas protegidas por el DIH tienen derecho a que se respete su vida y su integridad física y moral, y se benefician de garantías judiciales. Las personas serán, en todas las circunstancias, protegidas y tratadas con humanidad, sin distinción alguna de índole desfavorable.

En particular, está prohibido matar o herir a un adversario que haya depuesto las armas o que esté fuera de combate. Los heridos y los enfermos serán recogidos y asistidos por la parte beligerante en cuyo poder estén. Se respetarán el personal y el material médico, los hospitales y las ambulancias.

Las personas que no entran en la categoría de prisioneros de guerra (PG) se encuentran protegidos por la G-IV relativa a la protección de civiles en tiempos de guerra. Todas las personas detenidas caen en alguna de las categorías establecidas en ambas convenciones. No hay estatus intermedio, nadie en manos del enemigo está fuera de la ley.

hayan depuesto las armas y las personas puestas fuera de combate por enfermedad, herida, detención o por cualquier otra causa, serán, en todas las circunstancias, tratadas con humanidad, sin distinción alguna de índole desfavorable, basada en la raza, el color, la religión o la creencia, el sexo, el nacimiento o la fortuna, o cualquier otro criterio análogo. A este respecto, se prohíben, en cualquier tiempo y lugar, por lo que atañe a las personas arriba mencionadas: $a$ ) los atentados contra la vida y la integridad corporal, especialmente el homicidio en todas sus formas, las mutilaciones, los tratos crueles, la tortura y los suplicios; $b$ ) la toma de rehenes; c) los atentados contra la dignidad personal, especialmente los tratos humillantes y degradantes; $d$ ) las condenas dictadas y las ejecuciones sin previo juicio ante un tribunal legítimamente constituido, con garantías judiciales reconocidas como indispensables por los pueblos civilizados. 2) Los heridos y los enfermos serán recogidos y asistidos. Un organismo humanitario imparcial, tal como el Comité Internacional de la Cruz Roja, podrá ofrecer sus servicios a las Partes en conflicto. Además, las Partes en conflicto harán lo posible por poner en vigor, mediante acuerdos especiales, la totalidad o parte de las otras disposiciones del presente Convenio. La aplicación de las anteriores disposiciones no surtirá efectos sobre el estatuto jurídico de las Partes en conflicto".

25 Cfr. Caso Tadic, cit., nota 15, parágrafos 78-79, 83, 84, 91, 92 y 96-99. Véase también la opinión separada del juez Georges Abi-Saab en la misma decisión. En el mismo sentido, Boelaert Suominen, Sonja, "Grave Breaches, Universal Jurisdiction and Internal Armed Conflict: Is Customary Law Moving Towards a Uniform Enforcement Mechanism for All Armed Conflicts?", Journal of Conflict and Security Law, vol. 5, núm. 1, 2000, passim. 


\section{RELACIÓN ENTRE DERECHOS HUMANOS Y DIH ${ }^{26}$}

Es importante hacer la distinción entre derecho internacional humanitario y derecho internacional de los derechos humanos (DIDH). Aunque algunas de sus normas son similares, estas dos ramas del derecho internacional se han desarrollado por separado y figuran en tratados diferentes. En particular, el DIDH es, en términos generales, aquel cuerpo del derecho internacional que protege los derechos civiles, políticos, sociales, económicos y culturales de los seres humanos. El DIDH establece obligaciones "negativas" para los Estados, que se traducen en un no-violar dichos derechos humanos. También establece obligaciones "positivas" como tomar todas las medidas necesarias para asegurar su protección y realización. El DIDH es aplicable en tiempo de paz y muchas de sus disposiciones pueden ser suspendidas durante un conflicto armado, por ejemplo, el derecho de reunión. Sin embargo, existe un mínimo de derechos básicos ${ }^{27}$ que no pueden ser suspendidos bajo ninguna circunstancia, ni siquiera durante la guerra, como lo es el derecho a no ser torturado. ${ }^{28}$

La relación entre el DIDH y el DIH, cuando se trata de su aplicación en situaciones de guerra, es como la de un sistema de engranaje. En este caso todo lo que no se encuentre cubierto por el DIH estará cubierto, de manera subsidiaria, por el DIDH, el cual otorga, de manera más detallada, una mayor protección a los prisioneros. En el presente trabajo sólo nos limitaremos al DIH.

26 Véase, por ejemplo, Vité, Sylvain y Doswald-Beck, Louise, "International Humanitarian Law and Human Rights Law”, International Review of the Red Cross, núm. 293, 1993, passim.

27 Muchos de estos derechos básicos se encuentran en los instrumentos internacionales que constituyen lo que ha sido llamado como la "Carta Internacional de los Derechos Humanos", integrada por la Declaración Universal de los Derechos Humanos; Pacto Internacional de los Derechos Económicos, Sociales y Culturales; Pacto Internacional de Derechos Civiles y Políticos y su Protocolo Facultativo, así como el Segundo Protocolo Facultativo del mismo pacto destinado a abolir la pena de muerte.

28 En el caso, por ejemplo, de la Convención Americana, el artículo 27 indica que no son derogables los artículos: 3o. (derecho al reconocimiento de la personalidad jurídica); 4o. (derecho a la vida); 5o. (derecho a la integridad personal); 6o. (prohibición de la esclavitud y servidumbre); 90. (principio de legalidad y de retroactividad); 12 (libertad de conciencia y de religión); 17 (protección a la familia); 18 (derecho al nombre); 19 (derechos del niño); 20 (derecho a la nacionalidad), y 23 (derechos políticos), ni de las garantías judiciales indispensables para la protección de tales derechos. 


\section{LOS PRISIONEROS DE GUERRA, MARCO GENERAL}

El DIH establece normas específicas que regulan las condiciones de detención de los PG. La regla general es que cualquier combatiente capturado por el enemigo es un prisionero de guerra. La primer pregunta que surge es ¿quién puede ser considerado un PG?

Conforme al artículo 4o. de la III Convención, son PG ${ }^{29}$ "las personas que, perteneciendo a una de las siguientes categorías, caigan en poder del enemigo".

Esta primera fracción señala dos condiciones que, no obstante ser obvias, merecen ser comentadas. La primera es que para ser considerado PG es necesario caer en alguna de las seis posibles categorías aquí señaladas. La segunda condición es caer en manos del enemigo. En este sentido, enemigo es cualquier adversario en un conflicto armado, en su acepción más amplia que, sin importar las circunstancias, cae en poder de una de las partes beligerantes.

1. "Los miembros de las fuerzas armadas de una parte en conflicto, así como los miembros de las milicias y de los cuerpos de voluntarios que formen parte de estas fuerzas armadas".

La primera parte se refiere a los miembros de las fuerzas armadas, esto es, tanto a las fuerzas de aire, tierra, mar o cualquier otra categoría que pertenezcan al cuerpo militar de una de las partes. Se trata pues de lo que comúnmente se conoce como ejército en su aspecto profesional y concepto más amplio. Normalmente las fuerzas armadas portan uniforme, poseen un orden jerárquico y conocen las reglas del DIH.

En la segunda parte, que se refiere a milicias o cuerpos de voluntarios, son importantes mencionarlos porque en muchos Estados el grueso de las fuerzas armadas está conformado precisamente por este tipo de cuerpos. Generalmente, dichos cuerpos están conformados por miembros de la población civil que reciben entrenamiento militar y que en caso de conflicto armado son llamados a tomar su lugar en las fuerzas armadas.

29 El artículo 43-45 del P-I también define a los PG, tomando en cuenta las características del tipo de los conflictos armados que surgieron en el mundo después de la Segunda Guerra Mundial. Véanse comentarios en Cassese, Antonio, International Law, Oxford University Press, Gran Bretaña, 2001, pp. 329-332. Sin embargo, Estados Unidos de América no forma parte de dicho protocolo. Por esta razón, para los efectos del presente trabajo, nos limitaremos a lo indicado por el G-III. 
En el caso particular del conflicto en Afganistán, los talibanes bien pueden ser considerados las fuerzas armadas de Afganistán, y los miembros de Al Qaeda miembros de las milicias o cuerpos de voluntarios que forman parte de dichas fuerzas.

2. "Los miembros de las otras milicias y de los otros cuerpos de voluntarios, incluidos los de movimientos de resistencia organizados, pertenecientes a una de las Partes en conflicto y que actúen fuera o dentro del propio territorio, aunque este territorio esté ocupado, con tal de que estas milicias o estos cuerpos de voluntarios, incluidos estos movimientos de resistencia organizados, reúnan las siguientes condiciones: a) estar mandados por una persona que responda de sus subordinados; $b$ ) tener un signo distintivo fijo, reconocible a distancia; c) llevar las armas a la vista; d) dirigir sus operaciones de conformidad con las leyes y costumbres de la guerra".

Esta segunda categoría tiene una razón histórica ya reconocida en la Convención de La Haya de 1907. ${ }^{30}$ La razón de su inclusión fue debido a la, por así decirlo, atomización de los conflictos que habían tenido lugar en Europa. En dichos conflictos surgieron un sinnúmero de cuerpos de milicianos, y era, por lo tanto, necesario tratar de reconocer y otorgar a aquellos grupos de personas una protección jurídica. La misma problemática se presentó, durante la Segunda Guerra Mundial en donde al lado de los grandes ejércitos también peleaban numerosos grupos de "partisanos" a quienes, en ocasiones, se les otorgó la protección de prisionero de guerra.

Para hacerse acreedores del estatuto de prisioneros de guerra, estos cuerpos de combatientes debían reunir ciertos requisitos.

El primer requisito se refiere a la existencia de un orden jerárquico, en donde hay quien emite órdenes y quien las obedece; lo que hace más fácil la determinación de responsabilidades.

30 Estas mismas condiciones fueron en un principio señaladas en el artículo 1o. del Reglamento relativo a las leyes y costumbres de la guerra terrestre de la Cuarta Convención de la Haya de 18 de octubre de 1907 que indica: "Calidad de Beligerante. Art. 1. Las leyes, los derechos y los deberes de la guerra no se refieren solamente al ejército sino también a las milicias y a los Cuerpos de voluntarios que reúnan las condiciones siguientes: 1 . Tener a la cabeza una persona responsable por sus subalternos; 2. Tener una señal como distintivo fijo y reconocible a distancia; 3 . Llevar las armas ostensiblemente; 4. Sujetarse en sus operaciones a las leyes y costumbres de la guerra. En los países en que las milicias o los Cuerpos de voluntarios formen el ejército o hagan parte de él, tanto aquéllas como éstos quedan comprendidos bajo la denominación de ejército". 
El segundo requisito se trata de un signo distintivo que deben de portar los combatientes. Esto es esencial ya que, a falta de uniforme, los combatientes deben de diferenciarse del resto de la población civil.

En tercer lugar, el de portar las armas a la vista es un requisito que, como señala el CICR, no debe de entenderse en el sentido de poner en detrimento el factor sorpresa en cualquier operación militar.

Idealmente cualquier combatiente en un conflicto armado debería de conocer las reglas del DIH, sin embargo, esto no es así. El CICR reconoce que los combatientes:

In all their operations, they must be guided by the moral criteria which, in the absence of written provisions, must direct the conscience of man; in launching attacks, they must not cause violence and suffering disproportionate to the military result which they may reasonably hope to achieve. They may not attack civilians or disarmed persons and must, in all their operations, respect the principles of honour and loyalty as they expect their enemies to do. ${ }^{31}$

En el conflicto en Afganistán podría argumentarse que los miembros de Al Qaeda no reúnen las condiciones antes enumeradas, sin embargo, esto tiene que ser determinado ante la instancia judicial correspondiente, como veremos adelante.

3. "Los miembros de las fuerzas armadas regulares que sigan las instrucciones de un gobierno o de una autoridad no reconocidos por la potencia detenedora".

Esta disposición es de gran importancia, ya que ninguna de las partes beligerantes por el simple hecho de desconocer a la autoridad de su enemigo puede no otorgar el estatus de PG a los combatientes del mismo. Así, por ejemplo, durante la Segunda Guerra Mundial a las fuerzas del general De Gaulle se les pretendía no considerar PG debido a que las fuerzas del Eje no reconocían al gobierno de De Gaulle en el exilio. La solución que se dio fue la de asociar a éstas fuerzas a una de las partes beligerantes en este caso, que se encontraban peleando por el Reino Unido.

Tratándose del conflicto afgano, EUA no pueden argumentar que debido a que el gobierno de facto de los talibanes nunca fue reconocido por

31 Cfr. Pictet, Jean (ed.), Commentary on the Convention (III) relative to the Treatment of Prisoners of War. Geneva, 12 de agosto de 1949, ICRC, International Humanitarian Law, CD-ROM, 1998 (ICRC CD ROM). 
ellos, no pueden otorgar el estatus de PG a las personas capturadas durante dicho conflicto armado. ${ }^{32}$

4. "Las personas que sigan a las fuerzas armadas sin formar realmente parte integrante de ellas, tales como los miembros civiles de tripulaciones de aviones militares, corresponsales de guerra, proveedores, miembros de unidades de trabajo o de servicios encargados del bienestar de los militares, a condición de que hayan recibido autorización de las fuerzas armadas a las cuales acompañan, teniendo éstas la obligación de proporcionarles, con tal finalidad, una tarjeta de identidad similar al modelo adjunto".

Este artículo se refiere a las personas que acompañan a las fuerzas armadas sin ser miembros de ellas. Si bien este artículo hace referencia a la necesidad de que las fuerzas armadas deben de proporcionar una tarjeta de identidad a las personas que las acompañan, este requisito, en opinión del CICR, no es absoluto. El factor determinante, destaca el CICR, es la capacidad en la cual la persona estaba sirviendo, siendo la tarjeta de identidad una garantía suplementaria. ${ }^{33}$

5. "Los miembros de las tripulaciones, incluidos los patrones, los pilotos y los grumetes de la marina mercante, y las tripulaciones de la aviación civil de las Partes en conflicto que no se beneficien de un trato más favorable en virtud de otras disposiciones del derecho internacional".

Esta fracción establece la protección para los miembros de tripulaciones de la marina mercante o de la aviación civil, quienes por la naturaleza de sus actividades pueden encontrarse bajo el poder de una de las partes beligerantes.

6. "La población de un territorio no ocupado que, al acercarse el enemigo, tome espontáneamente las armas para combatir contra las tropas invasoras, sin haber tenido tiempo para constituirse en fuerzas armadas regulares, si lleva las armas a la vista y respeta las leyes y las costumbres de la guerra".

Este es el caso de los levantamientos en masa de una población para hacer frente a un enemigo invasor. En esta ocasión las condiciones para ser considerado PG se reducen solamente a dos y no a las cuatro del

32 Véanse comentarios en Human Rights Watch, Background Paper on Geneva Conventions and Persons Held by the US Forces, 19 de enero de 2002, p. 6.

33 El CICR indicó: "The Conference considered that the capacity in which the person was serving should be a determining factor; the possession of a card is not therefore an indispensable condition of the right to be treated as a prisoner of war, but a supplementary safeguard". Véase ICRC CD ROM, op. cit., nota 31 . 
párrafo segundo. Las condiciones son: llevar las armas a la vista y el respeto de las leyes y las costumbres de la guerra.

En esta categoría también pueden entrar algunas de las personas detenidas en Afganistán.

Así, los supuestos que va cubriendo este artículo van de lo más particular a lo más general. Desde las fuerzas armadas regulares hasta los levantamientos espontáneos de la población. En este sentido, un grupo de PG puede estar formado por personas que pertenecen a una de las diferentes categorías ya mencionadas. No es necesario que todos se encuentren bajo un mismo supuesto.

En la parte B del mismo artículo 4o. se señala que también se les otorgará el trato de PG al personal militar que se encuentre en un territorio ocupado y al personal militar que se encuentra internado en un país neutro.

Este mismo artículo no afecta al estatuto del personal sanitario y religioso, como se estipula en el artículo 33 del presente convenio. ${ }^{34}$

El artículo 5 del G-III señala que éste convenio se aplicará a las personas mencionadas en el artículo 4o. a partir del momento en que caigan en poder del enemigo y hasta su liberación y su repatriación definitiva. Asimismo, indica que en caso de duda respecto a la pertenencia a una de las categorías enumeradas en el artículo 4o. de las personas que hayan cometido un acto de beligerancia y que hayan caído en poder del enemigo, dichas personas se beneficiarán de la protección del presente convenio, en espera de que un tribunal competente haya determinado su estatuto. ${ }^{35}$

Dos son los principios fundamentales en este artículo. El primero es la de la aplicación del G-III, y por extensión, de toda la protección del $\mathrm{DIH}$, para aquellas personas que caigan en poder del enemigo. El segundo principio es que aún cuando se tenga duda sobre el estatus de la persona hecha prisionera, ésta deberá de gozar de la protección del convenio hasta que un tribunal competente determine su estatus. Este tribunal se entiende que debe de ser el mismo al que normalmente acudirían los miembros de las fuerzas armadas de la potencia detenedora en caso de conflicto en la aplicación del DIH.

34 El artículo 33 señala que los miembros del personal sanitario y religioso retenidos en poder de la potencia detenedora para asistir a los PG no serán considerados como tales. Sin embargo, disfrutarán, por lo menos, de todas las ventajas y de la protección del G-III, así como de cuantas facilidades necesiten para prestar sus servicios.

35 Véase también Green, Leslie C., The Contemporary Law of Armed Conflict, 2a. ed., Gran Bretaña, Juris Publishing y Manchester University Press, 2000, p. 198. 
En el caso que aquí se estudia nos encontramos con la situación de que el gobierno de EUA en un principio descartó la aplicación del DIH; después, indicó que solo algunos de los prisioneros gozarían de algunas de las disposiciones del derecho de Ginebra tal como la del goce del estatus de PG. Todo esto sin haber acudido a la instancia judicial correspondiente para dirimir cualquier tipo de duda, sino simplemente por decisión del Ejecutivo. Esto constituye graves violaciones a los Convenios de Ginebra.

Es importante mencionar que a pesar de la negativa del gobierno de EUA de otorgar el estatus de PG a los detenidos en Guantánamo, organismos internacionales tales como la Oficina del Alto Comisionado de Derechos Humanos de Naciones Unidas ${ }^{36}$ y el CICR, ${ }^{37}$ y las ONG internacionales, como Amnistía Internacional y Human Rights Watch, han señalado la obligación clara de EUA de otorgar el estatus de PG, que por derecho les corresponde, a los prisioneros de Guantánamo, al igual que la aplicación del DIH.

Resulta interesante observar que el Parlamento Europeo en una resolución del 7 de febrero de 2002 externó su solidaridad con EUA en la lucha contra el terrorismo, pero expresó su preocupación ante las condiciones de detención de los prisioneros detenidos en la base estadounidense de Guantánamo. El Parlamento consideró que estos presos no reúnen las condiciones prescritas por los Convenios de Ginebra y que los estándares establecidos en estos convenios deberían revisarse con el fin de hacer frente a situaciones nuevas generadas por el desarrollo del terrorismo internacional. El Parlamento invitó, a las Naciones Unidas y a su Consejo de Seguridad, a adoptar una resolución con miras a la instauración de un tribunal competente para las cuestiones relacionadas con Afganistán y cuyo objetivo sea esclarecer el estatuto jurídico de los presos. ${ }^{38}$

36 Véase, por ejemplo, Statement of High Commissioner for Human Rights on Detention of Taliban and Al Qaida Prisoners at US Base in Guantanamo Bay, Cuba, 16 de enero de 2002. La OEA, al igual que la Comisión Interamericana de Derechos Humanos, han manifestado su apoyo a la lucha contra el terrorismo y al deseo de que las personas detenidas se les respeten sus derechos humanos. También han criticado la creación de comisiones militares. Véase Resolución sobre terrorismo y derechos humanos de la CIDH del 12 de diciembre de 2001.

37 Véase comunicado de prensa del CICR del 9 de febrero de 2002.

38 RSP/2002/2513, Resolución del Parlamento Europeo sobre las condiciones de detención de los presos en Guantánamo, 7 de febrero de 2002. 
El 25 de abril de 2002 el Parlamento Europeo aprobó otra resolución en la que hacía un llamado a que el estatus de los prisioneros de Guantánamo fuera clarificado, y además indicaba que el establecimiento de comisiones militares representaba una clara violación de las obligaciones internacionales de EUA, en particular del Pacto Internacional de Derechos Civiles y Políticos. En el mismo sentido se manifestó el alto representante para la Política Exterior y de Seguridad de la Unión Europea, Javier Solana, afirmando incluso que los detenidos en Guantánamo deberían de gozar del estatus de prisioneros de guerra. ${ }^{39}$

Es importante indicar que aún en el supuesto de que las personas detenidas fuesen juzgadas por un tribunal competente y se encontrase que no gozan del estatus de PG, esto no significa que estarían en una indefensión total, en particular, gozarían de la protección del convenio cuarto al igual que de aquellas reglas que formen parte del derecho consuetudinario internacional. ${ }^{40}$

\section{DERECHOS DE LOS PRISIONEROS DE GUERRA}

En esta sección haremos mención de algunos de los derechos conferidos por el G-III. Como ya se indicó, en todo aquello que no se encuentra explícitamente señalado en el DIH, se debe utilizar, de manera subsidiaria y en donde sea aplicable, el DIDH.

La regla general, en cuanto a garantías de los PG, es la de aplicar las mismas condiciones, derechos y deberes a los PG que tuvieren las fuerzas armadas de la potencia detenedora.

Nuestro análisis se abocará a dos grandes categorías a saber: trato humano y garantías judiciales.

\section{Trato humano}

Los PG deben de ser tratados humanamente todo el tiempo. Esto significa, entre otras cosas, que no deben de ser torturados, insultados o expuestos a la curiosidad pública. Debiéndoseles respetar su persona su dig-

39 Véase Washington Times, "EU Parliament slams US military tribunals", 25 abril 2002, http://www.washtimes.com/upi-breaking/25042002-083751-5834r.htm.

40 Un ejemplo de estas reglas se encuentran en el artículo 75 del P-I que se refieren a las garantías fundamentales y que establecen un estándar mínimo de tratamiento humano y de debido proceso legal que debe de ser respetado para todas las personas sin importar sus estatus. 
nidad, sin que deban de sufrir discriminación alguna, siendo una de las categorías la de la nacionalidad. ${ }^{41}$ Asimismo, el G-III establece que los derechos de los PG son derechos inalienables. ${ }^{42}$

Los prisioneros deben de ser colocados en instalaciones con condiciones similares a las que se encuentran las fuerzas de la potencia detenedora. De manera particular, se señala que dichas instalaciones para los PG deben estar adecuadamente iluminadas y ventiladas. Los PG sólo pueden ser internados en instalaciones que se encuentren en tierra con todas las medidas de higiene y salud posibles. A los PG se les debe proporcionar alimentos y atención médica. ${ }^{43}$

La evacuación o transferencia de los PG se efectuará siempre con humanidad y en condiciones que no deberán ser menos favorables de aquéllas que gozarían las fuerzas armadas de la potencia detenedora. ${ }^{44}$

Un primer comentario respecto a estos derechos es sobre su carácter inalienable. Esto es, no son renunciables de ninguna manera.

También es importante destacar las condiciones bajo las cuales las personas detenidas en Guantánamo han sido tratadas. Para su traslado de Afganistán a Cuba, los detenidos fueron sedados, encapuchados, afeitados, encadenados de pies y manos a los asientos, y llevaban incorporado un orinal portátil. Ya en prisión, en el denominado campamento Rayos X, fueron colocados en jaulas de acero, que se encontraban a la intemperie y con las lámparas encendidas todo el día. Las celdas medían 1.80 por 2.40 ms., y por sanitario tenían una cubeta. ${ }^{45}$

A finales de abril, los prisioneros fueron trasladados a otras instalaciones dentro de la misma base de Guantánamo, si bien éstas se encontraban en mejores condiciones, uno de los problemas es que son aún más pequeñas que las anteriores. ${ }^{46}$

41 Si bien ningún PG puede ser discriminado con base en su nacionalidad, la propia G-III en su artículo 47 condena el uso de mercenarios, los cuales no gozarían del estatus de PG. Hasta ahora, el gobierno de Estados Unidos de América no ha calificado a las personas detenidas en Guantánamo como mercenarios. Véase Green, Leslie C., op. cit., nota 35, pp. 114-117, 199.

42 Cfr. artículos 7-17.

43 Cfr. artículos 13-25.

44 Cfr. artículos 20 y 46.

45 Véase la descripción que hace el periódico El Mundo en http://www.elmundo.es/elmundo/2002/graficos/ene/s3/guantanamo/guantanamo.html. También "Nuevos prisioneros en Guantánamo", BBC Mundo, 2 de mayo de 2002, en http://news.bbc.co.uk/hi/spanish/news/newsid_1963000/1963854.stm visitado el 8 de mayo de 2002.

46 El nuevo campo de detención se llama Campo Delta con un costo de varios millones de dólares. En "Traslados en Guantánamo", BBC Mundo, 30 de abril de 2002, en http://news.bbc.co.uk/hi/spanish/news/newsid_1958000/1958927.stm visitado 8 de mayo 2002. 
Es indudable que el trato dado a las personas detenidas en Guantánamo ha sido denigrante y bien puede calificarse en muchos casos de tratos crueles e inhumanos, por lo que podría considerarse como tortura. EUA nunca trataría así a sus propias tropas.

Como indicamos en un principio, no existe un número exacto de todas las personas detenidas ni tampoco se sabe en donde se encuentran todos. Aquí cabe mencionar que pese a que el G-III establece claramente la obligación de que los PG deben estar en instalaciones que se encuentren en tierra, algunas personas han sido retenidas en embarcaciones militares estadounidenses como el USS Peleliu.

EUA también ha declarado que sólo darán a sus ciudadanos todas las garantías judiciales para su enjuiciamiento. Esto en sí mismo constituye una discriminación, y así se ha hecho en el caso del americano John Walker Lindh, quien ha recibido un trato completamente diferente al del resto de los prisioneros detenidos; no obstante haber sido capturado en las mismas condiciones que los demás. Sin embargo, aún en su caso se cometieron varios abusos. Varios medios de comunicación señalaron que soldados estadounidenses se tomaron fotos con el ciudadano americano Walker, presunto talibán, mientras éste permanecía esposado, atado a una camilla y con los ojos vendados. Incluso refieren que en algunas fotos le hacían señas obscenas. Esto, por supuesto, constituye un atentado a la dignidad de la persona, además de poder considerarse tortura. Argumento éste último que ya ha sido utilizado por los abogados defensores del señor Walker. ${ }^{47}$

\section{Garantías judiciales}

Los PG sólo pueden ser tratados por una corte militar o a menos que las leyes existentes de la potencia detenedora permitan de manera expresa que sean juzgados por cortes civiles. En ninguna circunstancia, los PG deberán ser juzgados por corte alguna que no ofrezca las garantías esenciales de independencia e imparcialidad generalmente reconocidas, y en particular no podrán ser sujetos a ningún procedimiento en donde no se les otorgue los derechos y medios de defensa necesarios reconocidos por el G-III. ${ }^{48}$ De acuerdo con el artículo 102, los PG sólo podrán ser válida-

47 Masters, Brooke A., "Prosecutors concede limits of their case against Lindh", Washington Post, 2 de abril de 2002, p. A11.

48 Cfr. artículo 84. 
mente sentenciados si lo fueron por las mismas cortes y conforme al mismo procedimiento con que hubieran sido juzgados los miembros de las fuerzas armadas de la potencia detenedora, y siempre y cuando se hubieren observado las disposiciones de esta convención en particular, aquellas que se refieren a los derechos y medios de defensa. ${ }^{49}$

Conforme al artículo 86, los PG podrán ser juzgados conforme a las leyes de la potencia detenedora por actos cometidos antes de ser capturados. Sin embargo, aún cuando sean sentenciados deberán de gozar de los beneficios de esta convención.

Las Convenciones de Ginebra no excluyen la posibilidad de juzgar y castigar a los prisioneros de guerra por crímenes de guerra, de lesa humanidad o alguno del orden común.

Los PG tienen derecho a apelar la sentencia con la posibilidad de que ésta sea anulada o modificada.

En cuanto a los interrogatorios, los PG sólo están obligados a proporcionar su nombre, rango, fecha de nacimiento y número de serie. Por supuesto, no deberán de estar sujetos a tortura alguna. ${ }^{50}$ Según algunos reportes periodísticos, tropas estadounidenses están llevando a cabo entrenamientos para la formación de interrogadores ahora llamados: human intelligence collectors en donde la línea para evitar la tortura es cada vez más difícil de distinguir. ${ }^{51}$

La aplicación de estos derechos por parte del gobierno estadounidense difiere mucho de lo prescrito por el DIH e incluso de la propia práctica de EUA. ${ }^{52}$ Así, agentes de EUA han declarado en varias ocasiones que en caso de duda sobre el estatus de una persona hecha presa por EUA en un conflicto armado, ésta deberá de ser tratada como PG hasta que su situación sea definida por un tribunal competente. Conforme al propio derecho militar estadounidense, dicha determinación deberá ser hecha por un tribunal militar compuesto por tres miembros, y cuyas decisiones deben de

49 Artículo 105.

50 Artículo 17.

51 "Thus, Sgt. Giersdorf tells students, 'You can put a source in any position you want. You can chain his legs to the chair, you can handcuff his hands behind him', force him to stand at attention or have military police thrust him to the ground. 'If [a prisoner] says it hurts, is it torture?' he asks. 'Yes' say several students. 'No. It is not' The sergeant corrects". Cfr. Bravin, Jess, "US Army Recruits Learn How to Grill at Interrogation School", Wall Street Journal Europe, 29 de abril de 2002, pp. A-1 y A-9.

52 Véase comentarios en Paust J., Jordan, "Military Commissions: some perhaps legal, but most unwise", 14 de noviembre de 2001. En archivo con el autor. 
ser tomadas por mayoría. La persona sujeta a juicio deberá asimismo gozar de un juicio justo. Esto entre muchas otras disposiciones. ${ }^{53}$

Pese a contar con disposiciones claras en el propio derecho estadounidense, el gobierno actual ha sostenido que las personas detenidas en Guantánamo son combatientes ilegales, y que si bien pudiesen ser tratadas conforme a los Convenios de Ginebra, EUA no estaría obligado a hacerlo. El secretario de defensa Donald Rumsfeld declaró el 11 de enero de 2002 que: "las personas presas son combatientes ilegales y por lo tanto no tienen ningún derecho bajo los Convenios de Ginebra. Hemos indicado que planeamos, para la mayor parte de ellos, tratarlos de una manera que sea razonablemente consistente con los Convenios de Ginebra, hasta donde sean apropiados". Es importante señalar que el término de combatientes ilegales no existe en derecho internacional. ${ }^{54}$ Asimismo, el secretario de defensa declaró que aún cuando las comisiones militares absolvieran a algunos de los prisioneros que se encuentran en Guantánamo, si el gobierno de los EUA considera a dichas personas "terroristas peligrosos", los seguiría manteniendo presos. Estas declaraciones del secretario de defensa se han dado en contradicción con lo dicho por otros altos miembros militares, quienes han indicado claramente las condiciones en las cuales han capturado a las personas que se encuentran en Guantánamo. Así, por ejemplo, el consejero general del Pentágono declaró que: "The people that we are detaining, for example in Guantánamo Bay, Cuba, are enemy combatants that we captured on the battlefield seeking to harm US soldiers or allies". 55

Esto es, EUA pretende decidir el cómo, cuándo, qué y hasta qué punto, si es que lo hacen, aplicarían el DIH. ${ }^{56}$ Estados Unidos de América no solo se encuentran en violación de sus obligaciones convencionales, sino también de todos aquellos principios del DIH que ya forman parte del derecho con-

53 Véase, por ejemplo: Lacey, M. y Bill, B. (eds.), US military Judge Advocate General operational Law Handbook, US, International Law and Operational Law Department, Judge Advocate Generals School, 2000, passim.

54 Véase Human Rights Watch, Background Paper on Geneva Conventions and Persons Held by the US Forces, 19 de enero de 2002.

55 Department of Defence news briefing, 21 de marzo de 2002, reproducido en Amnistía Memorandum, op. cit., nota 1, p. 12.

56 El secretario de defensa estadounidense declaro: "We have indicated that we do plan to, for the most part, treat [the prisoners] in a manner that is reasonably consistent with the Geneva Conventions, to the extent they are appropriate, and that is exactly what we have been doing", Department of Defense news briefing, 11 de enero de 2002, ibidem, p. 31. 
suetudinario internacional. Además de ir en contra de la propia práctica de EUA en la materia. ${ }^{57}$

Es importante indicar que EUA ha declarado que en su base militar de Guantánamo no se aplica la Constitución de EUA porque la soberanía la ejerce Cuba. Por lo tanto, los prisioneros no gozan de los derechos que otorga la Constitución, ni tampoco de la posibilidad de acceso a los tribunales civiles, por lo que únicamente les deja el camino de las comisiones militares. ${ }^{58}$

Desafortunadamente el tratamiento de los PG por otros Estados partícipes en la coalición internacional tampoco ha sido del todo homogéneo. Así, mientras Gran Bretaña ha decidido otorgar el estatus de PG a las personas que ha capturado, las fuerzas canadienses han preferido transferir a las personas capturadas por ellas a las fuerzas estadounidenses para que sean ellos los que hagan la determinación. ${ }^{59}$

Finalmente, cabe mencionar que el no cumplir con los derechos antes mencionados puede considerarse un crimen de guerra. ${ }^{60}$

\section{COMISIONES MILITARES}

El 13 de noviembre de 2001, el presidente de Estados Unidos de América emitió una orden militar para la detención, tratamiento y enjuiciamiento de algunas personas no nacionales de EUA en la guerra contra el terrorismo. En dicha orden se declaraba que:

1. Los ataques terroristas en instalaciones y contra ciudadanos estadounidenses han sido de tal escala que han creado un estado de conflicto armado.

2. Las personas sujetas a dicha orden serían todos aquellos que no fuesen ciudadanos estadounidenses y que formasen parte de alguna organización terrorista.

57 Amnistía Internacional ha señalado que: "The USA's 'pick and choose' approach to the Geneva Conventions is unacceptable, as its is failure to respect fundamental international human rights standards" idem. Véase también Human Rights Watch, Background Paper on Geneva Conventions and Persons Held by the US Forces, 19 de enero de 2002, passim.

58 Véase "U.S. praises court decision to throw out detainees' lawsuit", 22 de febrero de 2002, www.cnn.com/2002/LAW/2002/02/22/inv.justice.detainees.suit/index.html. Visitado el 7 de mayo.

59 Véase nota de Graham, Bradley, "British to turn over Prisioners to Afganis", Washington Post, 30 de abril de 2002, p. A01.

60 Véase G-III, artículo 130, y G-IV, artículo 147. Respecto a crímenes de guerra véase, por ejemplo: Benavides, Luis, "La obligación de los Estados de reprimir los crímenes de guerra como parte de una justicia internacional penal" Revista de Derecho Público Mexicano, México, ITAM, núm. 3, 2002, passim. 
3. En caso de ser juzgados, lo serían por violaciones a las leyes de la guerra y a otras leyes aplicables por los tribunales militares.

4. En el caso de las comisiones militares, no eran aplicables los principios de derecho ni las reglas de las pruebas que comúnmente son aplicables en los casos criminales ante las cortes de distrito.

5. Indica que las personas a juzgar deben de ser tratadas humanamente, sin distinción basada en raza, color, religión, género, nacimiento, riqueza o cualquier otro criterio similar (por supuesto olvidaron el de nacionalidad).

6. La pena de muerte es aplicable.

7. Indica que la defensa tendrá un juicio justo.

8. El acusado no tiene ningún derecho a buscar un recurso de manera directa o indirecta o bien que se hiciere en su representación ante cualquier corte de EUA o ante cualquier corte de otro país o ante algún tribunal internacional.

Esta orden militar fue ampliamente criticada por diversas organizaciones de derechos humanos tanto internacionales como estadounidenses. ${ }^{61}$

Parte de la incongruencia que han mostrado EUA en el tratamiento de los PG se encuentra precisamente en este documento. Se trata, por ejemplo, del hecho de considerar aplicables las leyes de guerra y juzgar a los prisioneros por violaciones a las mismas, pero no considerarlos PG conforme a los Convenios de Ginebra. También constituye una violación el disminuir el estándar de un juicio justo para el caso específico de las comisiones militares.

Pese a dicha reacción, el gobierno de EUA emitió, el 21 de marzo de 2002 , otra orden militar en la que establece las reglas de procedimiento de las comisiones militares.

Algunas de las características son:

1. El secretario de defensa es quien establece las comisiones militares.

2. Dichas comisiones militares estarán formadas por un mínimo de tres y un máximo de siete miembros.

3. Los miembros de las comisiones deberán de ser oficiales militares, pero sólo el presidente de la comisión requiere ser abogado.

61 Véase lo sostenido por Amnistía Internacional, Human Rights Watch, The Center for Justice \& Accountability, Lawyers Committee for Human Rights, etcétera. Amnistía Internacional, por ejemplo, señaló que dicha orden debía de ser revocada por que amenazaba principios internacionales de justicia, incluyendo la separación de poderes, la no discriminación, entre otros tantos, en "Presidential oder on military tribunals threatens fundamentals principles of justice", 15 de noviembre de 
4. La jurisdicción de la comisión será sobre violaciones a las leyes de guerra y a "otras ofensas" que puedan ser juzgadas por comisiones militares (no dice cuáles son esas otras ofensas).

5. Se requiere dos terceras partes de los votos para encontrar culpable a una persona.

6. Se puede incluso aplicar la pena de muerte. Pero ésta solamente podrá ser aplicada por una comisión de siete miembros.

7. Una decisión tomada por la comisión puede ser apelable ante un panel de revisión de tres oficiales militares, en el cual uno deberá tener experiencia como juez.

8. El panel de revisión puede regresar el caso a la comisión que conoció de él o enviarlo al secretario de defensa. Este último puede regresar nuevamente el caso para ser juzgado o bien enviarlo al presidente para que emita una decisión final.

9. La sentencia de la comisión es final cuando el presidente de EUA o el secretario de defensa emiten una decisión definitiva para tal efecto.

Entre los derechos que contemplan dichas reglas de las comisiones destacan: el hacer públicos los juicios, probar más allá de una duda razonable, la existencia de una presunción de inocencia, el otorgar acceso al abogado defensor a los documentos de la fiscalía para preparar su caso, cuestionar a testigos y el derecho del acusado a no testificar en su contra.

Estas disposiciones se encuentran aún muy lejos de cumplir con el estándar mínimo internacional de derechos humanos, y para ello tomaremos como ejemplo el derecho a la presunción de inocencia. Es imposible pensar que se cumple con el derecho a la presunción de inocencia cuando el presidente de EUA ha declarado, con respecto a las personas detenidas en Guantánamo, que: "These killers-these are killers". El secretario de defensa también ha declarado en diferentes ocasiones, con respecto a las mismas personas que son: "hard-core well trained terrorists" y "among the most dangerous, best trained, vicious killers on the face of the earth". ${ }^{62}$

Estas declaraciones son extremadamente graves cuando son precisamente tanto el presidente como el secretario de defensa quienes establecen las comisiones en las cuales los detenidos en Guantánamo serán juzgados y quienes toman la decisión final sobre su suerte. Además, al ser 
dichas comisiones creadas por el Ejecutivo, difícilmente se puede hablar de órganos independientes de impartición de justicia.

\section{CONCLUSIONES}

La determinación del estatus jurídico de cualquier persona detenida durante un conflicto armado es esencial para saber los derechos que les son conferidos por el DIH. Asimismo, las obligaciones que tienen los Estados, con respecto a dichos prisioneros, son esenciales para determinar, en caso de violación de las mismas, las consecuencias jurídicas a las que se hace acreedor el Estado que los detiene.

En el presente caso es claro que las personas actualmente detenidas en Guantánamo fueron capturadas durante el conflicto en Afganistán, y por lo tanto gozan de la protección del DIH. Se presume, dada la propia información de EUA, que dichas personas participaron en combates y que fueron capturadas en el transcurso de los mismos. Este hecho les confiere el estatus de prisioneros de guerra. El DIDH, al igual que el derecho consuetudinario en la materia, vienen a complementar cualquier laguna que pudiese existir en cuanto al tratamiento que se debe de otorgar a los prisioneros de guerra.

EUA ha querido negar el estatus de prisioneros de guerra a las personas detenidas en Guantánamo, calificándolos a priori de terroristas y criminales, por lo que en su opinión serían combatientes ilegales. La determinación de dicho estatus no depende de la voluntad de la potencia detenedora, sino de cumplir o no con las condiciones anteriormente expuestas, que de manera objetiva señala el Convenio de Ginebra. En caso de duda sobre la pertenencia o no a dicha categoría, esto debe de ser determinado por una corte judicial.

La descalificación que EUA ha pretendido hacer del DIH de derecho obsoleto e inadecuado no tiene fundamento. Responde, en cambio, a una política con una doble finalidad, por una parte se busca justificar su actuación, y en caso de no poder hacer eso, trata de crear excepciones a las reglas ya existentes que legalicen sus actuaciones.

El tratamiento que EUA está otorgando a los detenidos en Guantánamo es violatorio del derecho internacional general y del humanitario en particular, por esta razón EUA es internacionalmente responsable por el trato dado a las personas detenidas en Guantánamo. ${ }^{63}$ 
En conclusión, con respecto a México podemos decir lo siguiente. El no oponernos a dichas acciones o por lo menos el no declararlas ilegales $a b$ initio nos pone en una posición muy riesgosa, debido a que:

1. La aquiescencia a dichas reglas puede dar lugar al nacimiento de nuevos derechos que pueden adquirir fuerza de costumbre internacional en la que no podríamos declararnos objetores persistentes, con todas las consecuencias que esto conlleva.

2. El no actuar también conlleva una responsabilidad - recuérdese que también se es responsable por omisión-. Muchas de las violaciones cometidas constituyen obligaciones erga omnes, en donde todos los Estados tienen un derecho legítimo para hacerlas respetar. También existe, claro está, una responsabilidad moral que es digna de consideración.

3. La violación de un, incipiente sí, pero importante Estado de derecho internacional, debe de preocuparnos a todos.

En un momento en el cual la Secretaría de Relaciones Exteriores declara que denunciaría violaciones de derechos humanos en cualquier lugar, ${ }^{64}$ habría que recordar al secretario que el silencio en la formación de reglas de derecho internacional tiene un precio, y éste puede ser muy caro de pagar.

Convenios o del presente Protocolo estará obligada a indemnizar si hubiere lugar a ello. Será responsable de todos los actos cometidos por las personas que formen parte de sus fuerzas armadas." Además de las reglas aplicables de la responsabilidad internacional.

64 "Acudo a este foro con el mandato de mi gobierno y de la sociedad mexicana para manifestar nuestro nuevo compromiso de respetar y contribuir con la comunidad internacional para que se respeten en todo el mundo los derechos humanos. El gobierno de México ha escogido este foro para presentar una serie de acciones que dan testimonio de un cambio fundamental en nuestra política hacia estos valores trascendentales... Se ha sostenido que la defensa y la promoción de los derechos humanos constituyen asuntos internos de cada país que no deben sujetarse al escrutinio internacional. México no comparte esta tesis. Afirma categóricamente que los derechos humanos representan valores con validez absoluta y universal... En tanto que valores universales, la situación de los derechos humanos en cualquier Estado es una preocupación legítima de la comunidad internacional en su conjunto. La labor de promover su vigencia y respeto es empresa común de todos los gobiernos y todos los pueblos, y no puede estar supeditada a la exclusiva voluntad de un gobierno... Es importante evitar que motivos ulteriores desvirtúen una iniciativa destinada a promover los derechos humanos. Por ello, favorecemos un tratamiento equilibrado, sobre bases objetivas y no selectivas, de la situación de los derechos humanos en el mundo y reiteramos nuestro interés indeclinable por trabajar a favor de los derechos humanos en todos los Estados. Nuestra voz será clara y nuestro voto reflejará el contexto real y objetivo en el que se emita". Palabras del secretario de relaciones exteriores, doctor Jorge Castañeda, en el 57o. periodo de sesiones de la Comisión de Derechos Humanos de la ONU, Ginebra, Suiza, 20 de marzo de 2001. En http://www.sre.gob.mx/derechoshumanos/doctos_rel57cdh.doc visitado el 21 de mayo de 2002. 